\title{
Demonstration of an intracellular copper-binding protein by orcein staining in long-standing cholestatic liver diseases
}

\author{
M. SALASPURO ${ }^{1}$, AND P. SIPPONEN \\ From the Second Department of Medicine, Second Department and Central Laboratory of Pathology, \\ University of Helsinki, Helsinki, Finland
}

SUMMARY Liver biopsies from eight patients with primary biliary cirrhosis, two with chronic active hepatitis of a cholestatic form, three with long-standing alcoholic liver cirrhosis, and one with extrahepatic biliary obstruction were studied. In each case dark brown cytoplasmic material was seen after staining of the tissue sections with Shikata's orcein method. In exactly the same cellular and subcellular locations as the orcein-positive material, and with morphologically equal granules, two different ordinary staining methods for copper (rubeanic acid and Mallory-Parker's haematoxylin) gave positive reactions. The earlier histochemical findings have revealed the protein nature and high sulphydryl content of the orcein-positive material. Its close association with copper in liver sections suggests its copper-binding nature and indicates that a common copper-protein complex accumulates in the cytoplasm of liver cells during longstanding cholestasis in biliary diseases of various pathogenetic origin.

There is a growing interest in the role of copper in the pathogenesis of primary biliary cirrhosis (PBC) (Leeson and Fourman, 1967; Fleming et al., 1974). This interest is supported by the fact that copper is a known hepatotoxin in experimental animals (Todd et al., 1962) and in Wilson's disease (Sternlieb, 1972). In an earlier study we demonstrated orcein-positive hepatocellular material in patients with PBC and suggested that it represents a means for differentiating histologically between PBC and chronic active hepatitis (Sipponen et al., 1975). Since hepatic copper concentrations are increased in PBC, the purpose of the present study was to compare histologically the location and the association of the orceinpositive material with the occurrence of copper. The analysis was also extended to some other longstanding cholestatic cases of origin other than PBC, in which orcein-positive hepatocellular material can be demonstrated (Salaspuro et al., 1976b).

\section{Methods}

PATIENTS

Needle or concotomy biopsies were obtained at

\footnotetext{
${ }^{1}$ Address for reprint requests: Dr M. Salaspuro, Second Department of Medicine, University of Helsinki, 00290 Helsinki 29, Finland.
}

Received for publication 7 June 1976 laparoscopy from eight patients with $\mathrm{PBC}$ and from six other patients with cholestatic liver disease.

All the patients with PBC had suffered from the disease for more than three years. The clinical picture and laboratory findings were typical of primary biliary cirrhosis in every case (Sherlock and Scheuer, 1973). High titres of mitochondrial antibodies were detected in all patients. In addition, each patient had markedly raised levels of alkaline phosphatase and lgM-immunoglobulin. Histologically, all of the cases were already in the scarring and cirrhotic stage.

Two patients with chronic active hepatitis had an atypical, cholestatic form of the disease with an advanced liver cirrhosis. The other had developed the liver disease after ulcerative colitis. Both of them had moderate titres of smooth muscle antibodies.

Three patients had advanced alcoholic liver cirrhosis with jaundice. One patient, with an extrahepatic biliary obstruction, had a central hepatoma with jaundice of several months' duration.

\section{HISTOLOGICAL METHODS}

The neutral formalin fixed paraffin embedded needle, or concotomy liver biopsies were stained by the method of Shikata et al. (1974). Before staining, the $5-8 \mu$ tissue sections were oxidized in $0.3 \%$ potassium permanganate solution and decolourised in $1.5 \%$ oxalic acid. They were then stained for four 
hours in a solution of $4 \mathrm{~g}$ orcein (Merck) dissolved in $100 \mathrm{ml} \mathrm{70 \%} \mathrm{ethanol,} \mathrm{adjusted} \mathrm{to} \mathrm{pH} 2$ with $\mathrm{HCl}$.

Rubeanic acid stain and Mallory-Parker's haematoxylin reaction were used to demonstrate copper in the tissue sections (Culling, 1974).

\section{LABORATORY METHODS}

Immunoglobulins (IgG and IgM) were measured by radial immunodiffusion. Mitochondrial and smoothmuscle antibodies were detected by direct immunofluorescence (Wager et al., 1971). Standard laboratory methods were used to estimate the serum concentrations of aspartate- and alanine-aminotransferases and alkaline phosphatases.

\section{Results}

\section{LOCATION AND CHARACTERISTICS OF} ORCEIN-POSITIVE MATERIAL

Orcein-positive material was seen in specimens from all patients. It was located in the cytoplasm of periportal hepatocytes as coarse brown or black- brown granules and aggregates (Fig. 1), and there was a tendency toward focal accumulations. The quantity of the material seen varied from case to case but was more marked in patients with primary biliary cirrhosis. The morphology of the material differed from the inclusion bodies of Australia antigen (HBAg) and was never seen as single inclusions or membrane-associated bodies as reported in HBAg-positive cases by Shikata et al. (1974). Furthermore, all of the patients were serologically negative for HBAg.

\section{LOCATION OF COPPER}

Both the rubeanic acid and the Mallory-Parker's haematoxylin method for copper gave positive reactions in exactly the same locations where orceinpositive material was observed (Figs. 1, 2). The positive correlation with the orcein stain could be seen in all specimens. The morphology of the granules which were stained by rubeanic acid was similar to that of orcein-positive material. The clear correspondence of locations and the similarity of

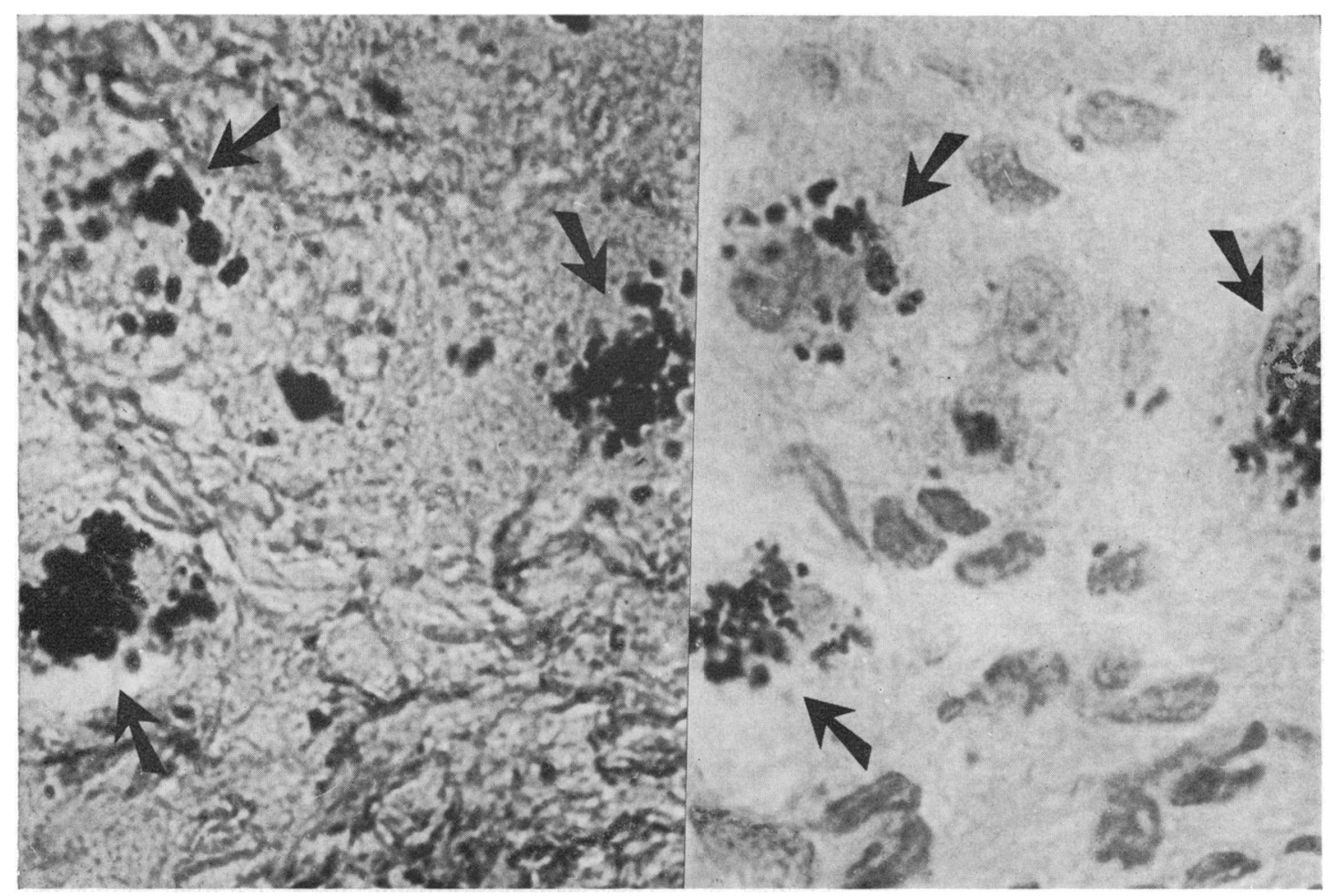

Fig 1

Fig 2

Fig 1 Orcein positive cytoplasmic material in liver cells in a patient with primary biliary cirrhosis. Same area as in Fig 2. Oxidated by potassium permanganate after rubeanic acid staining. Thereafter stained with orcein. $\times 400$. Fig 2 Copper (arrows) in liver cells in a patient with primary biliary cirrhosis. Rubeanic acid staining. Counterstained with neutral red. $\times 400$. 
morphology in staining reactions support the possibility of an association between copper and the orcein-positive material.

No differences could be observed in the staining properties of tissue sections from patients with primary biliary cirrhosis, with cholestatic liver disease associated with ulcerative colitis or chronic active hepatitis, or long-standing alcoholic liver cirrhosis. This suggests that the phenomenon is general and is common to different forms of long-standing cholestasis which are caused by the failure in biliary flow.

\section{Discussion}

Shikata and his colleagues (1974) have published details of a method for staining the hepatitis-B antigen (HBAg) in liver sections with orcein. A morphologically different type of periportal orceinpositive material was, however, found in 15 out of 18 cases with primary biliary cirrhosis (Sipponen et al., 1975). The same material could also be demonstrated in some cases of the cholestatic form of chronic active hepatitis and also occasionally in some cases of longstanding liver cirrhosis (Salaspuro et al., 1976b). The clinical picture of orcein-positive cases is characterised (Salaspuro et al., 1976a) by a marked rise in serum alkaline phosphatase, leucine aminopeptidase, cholesterol, bile acids, and highly pathological BSP Tm-values as well as a poor response to ordinary immunosupressive treatment of chronic active hepatitis.

The nature and chemical composition of the orceinpositive material is not completely known. In histochemical analysis it can be differentiated from bile pigments, lipofuscins, lipids, iron inclusions, $\alpha_{1^{-}}$ antitrypsin, and the normal constituents of liver cells (Sipponen, 1976). It behaves, during staining, like a protein that contains sulphydryl residues in high amounts, thus suggesting that the orcein-positive material is protein in nature (Sipponen, 1976).

The orcein method of Shikata et al. (1974) contains an oxidative step in the staining procedure. Copper cannot be demonstrated histochemically (Sipponen, 1976) or by microprobe analysis after this procedure (Sipponen et al., 1976), which suggests the dissociation of the copper-protein complexes and dissolution of copper during the procedure. On this basis the possibility that orcein stains copper can be excluded. The oxidation is, on the contrary, necessary for the demonstration of the orcein-positive accumulations. This suggests that the orcein stain has an affinity for sulphonic acid residues induced from sulphydryl groups during oxidation.

The finding that copper and the orcein-positive material can be observed in the same location suggests the occurrence of protein-copper complexes.
The biochemical counterpart of orcein-positive material could be one of the copper binding proteins -that is, metallothionein (Evans et al., 1973). Metallothionein is known to contain sulphydryl groups in large quantities and it binds copper to the apoprotein, thionein, through these residues by the formation of mercaptides (Morell et al., 1961; Evans, 1973). These observations correspond with the observed characteristics of orcein-positive accumulations supporting the hypothesis that thionein and orcein-positive aggregations are related.

Schematically the results can be presented as follows:

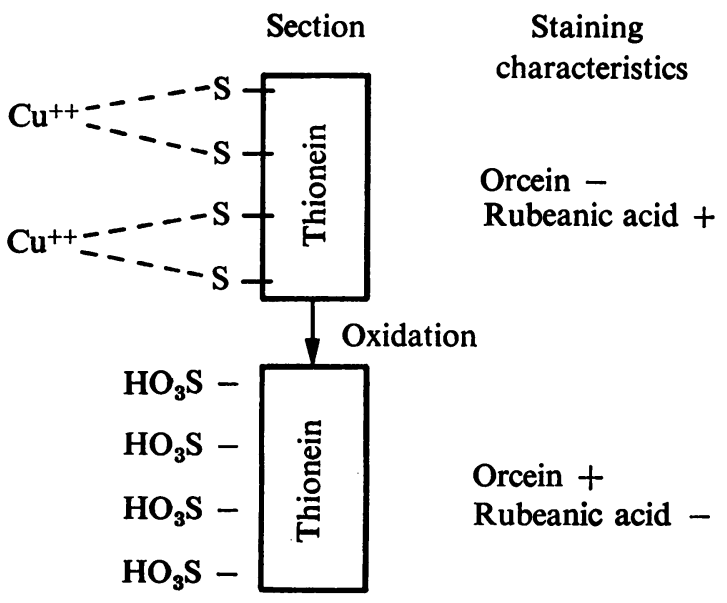

The accumulation of copper in liver cells can be demonstrated, therefore, either by staining copper itself or by showing the apoprotein part of the intracellular complexes with the orcein method.

The pathogenetic role of excessive copper-protein accumulation during cholestasis remains to be resolved. Raised copper levels, Wilson's disease apart, have been found especially in patients with biliary cirrhoses (Hunt et al., 1963; Worwood et al., 1968). In extrahepatic cholestasis increased amounts of copper can be demonstrated only after several months of obstruction (Smallwood et al., 1971). Studies of copper kinetics with radioactive copper in patients with PBC have shown that unlike the findings in Wilson's disease, hepatic uptake, incorporation into caeruloplasmin, and plasma clearance are all normal (Gibbs and Walshe, 1971; Smallwood et al., 1971).

Copper is known to be a hepatotoxin (Todd et al., 1962). Therefore, it seems quite possible that copper might contribute to the development of liver cirrhosis in long-standing liver cholestasis. The role of penicillamine in the possible dissolution of the 
orcein-positive copper-protein complex is under investigation.

\section{References}

Culling, C. F. A. (1974). Handbook of Histopc thological and Histochemical Techniques, 3rd edn, p. 712. Butterworth: London.

Evans, G. W. (1973). Copper homeostasis in the mammalian system. Physiological Revien's, 53, 535-570.

Evans, G. W., Dubois, R. S., and Hambidge, K. M. (1973). Wilson's disease: identification of an abnormal copperbinding protein. Science, 181, 1175-1176.

Fleming, C. R., Dickson, E. R., Baggenstoss, A. H., and McCall, J. T. (1974). Copper and primary biliary cirrhosis. Gastroenterology, 67, 1182-1187.

Gibbs, K., and Walshe, J. M. (1971). Studies with radioactive copper $\left({ }^{64} \mathrm{Cu}\right.$ and $\left.{ }^{67} \mathrm{Cu}\right):$ the incorporation of radioactive copper into caeruloplasmin in Wilson's disease and in primary biliary cirrhosis. Clinical Science, 41, 189-202.

Hunt, A. H., Parr, R. M., Taylor, D. M., and Trott, N. G. (1963). Relation between cirrhosis and trace metal content of liver: with special reference to primary biliary cirrhosis and copper. British Medical Journal, 2, 1498-1501.

Leeson, P. M., and Fourman, P. (1967). A disorder of copper metabolism treated with penicillamine in a patient with primary biliary cirrhosis and renal tubular acidosis. American Journal of Medicine, 43, 620-635.

Morell, A. G., Shapiro, J. R., and Scheinberg, I. H. (1961). Copper binding protein from human liver. In Wilson's Disease, Some Current Concepts. Edited by J. M. Walshe and J. N. Cumings. Blackwell: Oxford.

Salaspuro, M. P., Sipponen, P., Ikkala, E., Kolho, L., Makkonen, H. M., Miettinen, T. A., Räsänen, J. A., and Siurala, M. (1976a). Clinical correlations and significance of orcein-positivity in chronic active hepatitis and primary biliary cirrhosis. Annals of Clinical Research, 8, 206-215.

Salaspuro, M. P., Sipponen, P., and Makkonen, H. M. (1976b). The occurrence of orcein-positive hepatocellular material in various liver diseases. Scandinavian Journal of Gastroenierology. (In press.)

Sherlock, S., and Scheuer, P. J. (1973). The presentation of 100 patients with primary biliary cirrhosis. New England Journal of Medicine, 289, 674-678.

Shikata, T., Uzawa, T., Yoshiwara, N., Akatsuka, T., and Yamazaki, S. (1974). Staining methods of Australia antigen in paraffin section. Detection of cytoplasmic inclusion bodies. Japanese Journal of Experimental Medicine, 44, 25-36.

Sipponen, P. (1976). Orcein-positive hepatocellular material in long-standing biliary diseases. I. Histochemical characteristics. Scandinavian Journal of Gastroenterology. (In press.)

Sipponen, P., Hjelt, L., Törnkvist, T., and Salaspuro, M P. (1976). X-ray microanalysis of copper in liver sections in biliary cirrhosis. Archives of Pathology. (In press.)

Sipponen, P., Salaspuro, M. P., and Makkonen, H. M. (1975). Orcein-positive hepatocellular material in histological diagnosis of primary biliary cirrhosis. Annals of Clinical Research, 7, 273-277.

Smallwood, R. A., Mcllveen, B., Rosenoer, V. M., and Sherlock, S. (1971). Copper kinetics in liver disease. Gut, 12, 139-144.

Sternlieb, I. (1972). Evolution of the hepatic lesion in Wilson's disease (hepatolenticular degeneration). In Progress in Liver Diseases, vol. 4, pp.511-525. Edited by H. Popper and F. Schaffner. Grune and Stratton: New York.

Todd, J. R., Gracey, J. F., and Thompson, R. H. (1962). Studies on chronic copper poisoning. J. Toxicity of copper sulphate and copper acetate in sheep. British Veterinary Journal, 118, 482-491.

Wager, O., Räsänen, J. A., Haltia, K., and Wasastjerna, C. (1971). M components with antibody activity. Antismooth muscle, anti-thyroglobulin and anti-streptolysin-0 activity in five $\mathrm{M}$ component sera. Annals of Clinical Research, 3, 86-97.

Worwood, M., Taylor, D. M., and Hunt, A. H. (1968). Copper and manganese concentrations in biliary cirrhosis of liver. British Medical Journal, 3, 344-346. 